\title{
Adapting a maternity service during the COVID-19 pandemic: a commentary
}

\author{
Rahel-Ochido Odonde ${ }^{1}$ and Caroline Everden ${ }^{1}$ \\ ${ }^{1}$ Royal Surrey County Hospital NHS Foundation Trust
}

April 27, 2020

\section{Introduction}

On $11^{\text {th }}$ of March 2020 the World Health Organization declared the Coronavirus disease (COVID-19) outbreak a pandemic ${ }^{(1)}$. Human-to-human transmission of COVID-19 has been established and from the $16^{\text {th }}$ of March Public Health England (PHE), declared that vulnerable individuals including the pregnant population should be even more stringent about following the social distancing rules ${ }^{(2)}$. This decision was most likely informed by the knowledge that pregnancy changes the immune system, which can lead to the development of more severe symptoms following a viral infection. To date 148,377 people have tested positive for SARS-CoV2, with 20,319 of those hospitalised having sadly died in the $\mathrm{UK}^{(3)}$. The numbers of infected will no doubt include pregnant women and so every maternity unit should be as prepared as possible, in an ever evolving situation.

The Royal Surrey NHS Foundation Trust has a maternity unit that delivers approximately 2,700 babies annually. As a smaller obstetric unit we face different challenges in regards to our physical facilities and staffing, compared to larger obstetric units. We approached the need for rapid adaptation of our services using the following concepts as highlighted by the Centers for Disease Control and Prevention (CDC) ${ }^{(4)}$ : 1) limiting the entry of pathogens on to the unit, 2) isolating symptomatic patients or patients living with a symptomatic individual and 3) protecting our staff. We also, implemented the recommendations by the Royal College of Obstetricians and Gynaecologists $(\mathrm{RCOG})^{(5)}$, which aligned with the aforementioned concepts.

This article shares the practical steps we took, as well as the challenges and successes a small maternity unit have had so far in a dynamic climate, with constantly emerging and changing guidelines for providing evidence-informed clinical care during the COVID-19 pandemic.

Limiting the entry of pathogens onto the maternity unit

Structural changes that reduce patient flow throughout the maternity department were instigated early on, to minimise infection opportunities for both our women and staff, in groups thought to be negative, suspected or confirmed SARS-CoV2 positive. The hospital now only has two main entrance points. All patients arriving at the Accident and Emergency department (A\&E), are screened for symptoms and have their temperature taken. At the main entrance, entry is restricted to those with an appointment and visitors are only allowed under extraordinary circumstances.

Our pregnancy advice telephone service has COVID-19 symptom screening questions; aiding in the direction of pregnant women to designated 'hot' or 'cold' assessment areas in our unit. Details of these are discussed later in the commentary. Initially labelled 'dirty' and 'clean', our 'hot' areas are where patients suspected to have or with confirmed COVID-19 are reviewed and managed. Conversely, 'cold' areas are where women who are deemed low risk for having COVID-19 are seen.

In line with national guidance, the unit has streamlined obstetric antenatal clinics - offering telephone 
consultations as a default. Any woman who requires a face-to-face consultation as per clinical need is screened on arrival by the entrance to the outpatient department with questions and her temperature is taken.

Much of our community midwifery care is run from General Practice surgeries. As many reduced their face-to-face services, and we planned for lower staff numbers; we concentrated our community provision into two existing sites and one new central one - procured from a local private provider so as not to unduly increase footfall at the hospital. Informal feedback from our women via social media has been overwhelmingly positive, as they feel safer avoiding the main hospital. Where telephone consultations have replaced face to face appointments, as per the RCOG guidance ${ }^{(6)}$, a temporary 'drive-through' service allows blood pressure and urine dip checks.

\section{Isolating patients with a contact history or symptoms}

One of our main 'hot' areas is our designated 'pregnancy pod'. It is a stand-alone suite of clinical rooms that are situated directly behind our A\&E, that were repurposed. The suite is fully equipped with an assessment room, ultrasound machine, cardiotocograph and trolley available for emergency transfers. This area is for both emergency and routine attendances that cannot be postponed beyond the self-isolation period recommended by the Government. All pregnant women who have had contact with or are suspected of or confirmed COVID-19 enter via A\&E. As an extension of the 'hot' A\&E area, all staff working in the 'pregnancy pod' wear the appropriate personal protective equipment (PPE). We offer acute gynaecology, early pregnancy, antenatal and postnatal care in this environment.

On delivery suite, all rooms have ensuite bathrooms. Those with a double door were prioritised for COVID-19 suspected or confirmed cases. Retrofitting additional doors has also increased our isolation capacity.

\section{Protecting our staff}

Screening all women at entry and adequate provision of PPE are key to staff protection. Staff who require shielding, work from home completing telephone consultations. Those who do not meet criteria but nonetheless have medical comorbidities are prioritised to work at the 'drive-through'. The woman remains in her vehicle whilst blood pressure checks, blood tests and urine dips are carried out. Adjacent to the maternity 'drive-through', the pharmacy 'drive-through' allows collection of prescriptions from telephone consultations. All services are by appointment only to reduce congestion.

\section{Successes and challenges}

An effective response requires trust, efficiency, communication and leadership, at every level. Focused daily higher management briefings are cascaded across departments via clinical leads and directors. On a daily basis, department huddles address staffing and the current local COVID-19 situation. Attendance is limited to key clinical and managerial decision makers from all maternity areas: antenatal, postnatal, delivery ward and paediatrics. This allows us to respond immediately to arising challenges and ensures dissemination of information about predicted workload. Hospital-wide issues such as access to theatres, anaesthetic staffing and equipment levels are evaluated and responded to on a departmental level.

There is an overwhelming volume of information being received by staff. At our unit we discovered that the most up to date staff were engaged in national Whatsapp groups and Twitter. To prevent information overload and focus staff on information relevant to the unit a single daily update email is fed into by all staff. Virtual meetings via video conferencing ensure all staff have an opportunity to learn about upcoming changes and ask questions.

Information for the women booked with our unit has also been a key part of our response. Our Head of Midwifery conducts Facebook Live sessions, with all our social media channels regularly updated. Appreciation for the reasons behind changes made has improved their reception. Our local Maternity Voices Partnership, an independent forum for maternity service users, commissioners and other crucial stakeholders that reviews 
and collaborates on quality improvement work for local maternity $\operatorname{units}^{(7)}$, has been a key partner in this two-way communication.

Personal protective equipment (PPE) has presented its own unique challenge with ever changing guidance and availability. When national PPE guidance from $\mathrm{PHE}^{(8)}$ changed, we dealt with elevated anxiety levels amongst staff who felt that changes were either made too late or were being driven by supply issues rather than safety. Daily presence on the wards from our team leaders and being open about the uncertainty helped our staff. At the time of writing, daily emergency drills, with active consideration of required PPE are being carried out. Talking through the processes is not sufficient and all members of the multi-disciplinary team need to be involved.

Staffing concerns mean that we have prepared for staff to work outside their normal clinical areas. Homebirth and community midwives have been working in the hospital and ward staff have changed locations. Doctors have been stepping down to cover parts of the rota. For midwives we created a skills passport - a list of key skills each area required, and each midwife possessed. This allowed team leaders to appropriately allocate staff, and our practice development team to offer targeted training. In addition, our junior doctors created one page summaries of their key duties and 'how-to' guides to support senior staff stepping down.

We have focused on preserving essential parts of our service. Our key values remain unchanged and have been used as a guide when looking at changes required. When introducing change the following were considered:

- Avoid single points of failure: never have only one person critical to a process.

- Use the 'unit memory'. Past projects and ways of working have been scrutinised to evaluate the reasons for their success, failure, potential for amendment and utilisation in the current epidemic.

- Avoid duplication and wasted effort. Offers of help have been plentiful. Central coordination is essential to ensure any projects undertaken align with current priorities.

- Be prepared for local adaptation/interpretation of guidance. Where staff were found to be varying from the new guidelines we looked at why and considered if their approach was better.

The thread that brings everything together is transparent communication. This is a marathon and longevity requires engagement and commitment from all staff over the months ahead.

\section{Conclusion}

COVID-19 has been an opportunity for our maternity service to evaluate every aspect of how we deliver care. The steps taken to standardise care, increase evidence based practice and improve workforce planning have the potential to improve our standard of care long-term. Over the coming months, as the COVID-19 burden decreases, evaluation of these changes will be essential.

\section{Disclosure of interests}

None. There was no financial support. Completed disclosure of interest forms are available to view online as supporting information.

Contribution to Authorship

ROIO: Conceptualisation and planning. ROIO and CE: Manuscript writing, review and editing.

\section{Details of ethical approval}

There is no ethical approval applicable for this commentary.

\section{Acknowledgments}

None.

References 
1. WHO Director-General's opening remarks at the media briefing on COVID-19 - 11 March 2020 [Internet]. [cited 2020 Apr 12]. Available from: https://www.who.int/dg/speeches/detail/who-director-general-sopening-remarks-at-the-media-briefing-on-covid-19-11-march-2020

2. Guidance on social distancing for everyone in the UK - GOV.UK [Internet]. [cited 2020 Apr 12]. Available from: https://www.gov.uk/government/publications/covid-19-guidance-on-social-distancing-andfor-vulnerable-people/guidance-on-social-distancing-for-everyone-in-the-uk-and-protecting-older-people-andvulnerable-adults

3. Department of Health and Social Care and Public Health England. Number of coronavirus (COVID-19) cases and risk in the UK - GOV.UK [Internet]. 2020 [cited 2020 Apr 26]. Available from: https://www.gov.uk/guidance/coron covid-19-information-for-the-public

4. Infection Control: Severe acute respiratory syndrome coronavirus 2 (SARS-CoV-2) | CDC [Internet]. [cited 2020 Apr 12]. Available from: https://www.cdc.gov/coronavirus/2019-ncov/hcp/infection-controlrecommendations.html?CDC_AA_refVal=https\%3A\%2F\%2Fwww.cdc.gov\%2Fcoronavirus\%2F2019-ncov\%2Finfectioncontrol\%2Fcontrol-recommendations.html

5. RCOG, RCM. Information for healthcare professionals Guidance for antenatal and postnatal services in the evolving coronavirus (COVID-19) pandemic 2 [Internet]. London; 2020 [cited 2020 Apr 12]. Available from: https://www.rcog.org.uk/globalassets/documents/guidelines/2020-04-17-guidance-for-antenatal-andpostnatal-services.pdf

6. Ross-Davie M, Jaki L, Brigante L, Livingstone C, Crowe S, Pandya P, et al. Guidance for antenatal and postnatal services in the evolving coronavirus (COVID-19) pandemic [Internet]. London; 2020 [cited 2020 Apr 26]. Available from: https://www.rcog.org.uk/globalassets/documents/guidelines/2020-04-24-guidancefor-antenatal-and-postnatal-services.pdf

7. National Maternity Voices - Networking Maternity Voices Partnerships in England [Internet]. [cited 2020 Apr 26]. Available from: http://nationalmaternityvoices.org.uk/

8. Public Health England. COVID-19: infection prevention and control guidance [Internet]. 2020 [cited 2020 Apr 24]. Available from: https://www.gov.uk/government/publications/wuhan-novel-coronavirus-infectionprevention-and-control/wuhan-novel-coronavirus-wn-cov-infection-prevention-and-control-guidance 